See discussions, stats, and author profiles for this publication at: https://www.researchgate.net/publication/337061831

\title{
Language and the development of intercultural competence in an 'internationalised' university: staff and student perspectives
}

Article in Teaching in Higher Education · November 2019

DOI: 10.1080/13562517.2019.1686698

\section{CITATIONS}

4 authors:

Katie Dunworth

University of Bath

19 PUBLICATIONS 124 CITATIONS

SEE PROFILE

(2) Janina Iwaniec

University of Bath

9 PUBLICATIONS 45 CITATIONS

SEE PROFILE

Some of the authors of this publication are also working on these related projects:

Academic community development View project

Project The role of pedagogy in applied linguistics today View project
110

Trevor Grimshaw

University of Bath

11 PUBLICATIONS 136 CITATIONS

SEE PROFILE

Jim Mckinley

University College London

32 PUBLICATIONS 166 CITATIONS

SEE PROFILE 


\title{
Language and the development of intercultural competence in an 'internationalised' university: staff and student perspectives
}

\author{
Katie Dunwortha, Trevor Grimshawa, Janina Iwanieca and Jim McKinleyb \\ aDepartment of Education, University of Bath, UK; \\ bInstitute of Education, UCL, London, UK
}

This is an author-produced PDF of the final version of an article accepted for publication in TEACHING IN HIGHER EDUCATION. There is a two-year embargo (one year in the UK) before a reviewed version of the article can be published on an author website.

‘Early view’ online (first published) 6 November 2019 doi.org/10.1080/13562517.2019.1686698

\begin{abstract}
Within the currently diverse UK higher education environment, one important aspect of learning is the development of intercultural competence. The study that informs this paper investigated the ways intercultural competence was perceived as being enhanced or inhibited through current language and educational practices at a university that positions itself as internationally engaged and globally recognised. The project employed a multiple-case study design, examining eight academic programmes drawn from four different broad disciplinary groupings: social sciences, science, engineering, and management. Data were collected through individual, focus group and stimulated recall interviews, the latter using class observation recordings as a stimulus. The study revealed the ways in which language was exploited by both staff and students to convey particular meanings within an intercultural context. It was found that language choices, register and style were perceived as contributing to the pragmatic impact of either reinforcing barriers to or promoting intercultural competence development.
\end{abstract}

\section{Introduction}

Like many higher education institutions worldwide, the university at which this study took place is keen to promote a worldview that emphasises an international outlook, an inclusive approach and respect for difference. For example, the university's strategy (2016-21) describes its vision as including innovative and global modes of programme delivery and lists its values as including a commitment to fostering equality, diversity, inclusivity and accessibility. What is more, its student body, according to its website, comprises over 17,000 students, 30 per cent of whom are from outside the UK, and drawn from more than 130 countries. It is frequently taken as axiomatic that successful operation within and maintenance of such an environment requires 'intercultural competence' (e.g. HEA 2014; Jones 2013). Indeed, there is consensus that intercultural competence is a capacity that is also highly valued in a wide range of settings beyond higher education, including business (Freeman 2009) and 'transnational civil society' more broadly (Byram 2008).

In spite of its acknowledged importance, it is by no means certain that the development of intercultural competence is being successfully integrated into university teaching programmes. For example, the university in this study did not seem to have produced any policies or curriculum documents that referred to intercultural issues, and there was no specific intercultural component on its training programme for new staff. This absence of information provided the impetus for the project which, it was anticipated, would be able to provide some baseline data on which the university could draw in the future. 
The overall project had the objective of identifying how staff and students understood intercultural competence and the ways in which they perceived that it was instantiated, enhanced or inhibited through the teaching and learning practices they experienced. This was revealed both thematically, through the information, ideas and concepts that participants described, and also through the language choices that they made. Specifically, language use played a central role in two ways. First, the language that participants articulated provided further evidence of how they perceived notions of culture, interculturality and intercultural competence. Second, language was presented by participants as a tool which they or others employed to promote or create a barrier to the development of intercultural engagement and the growth of intercultural competence.

While the study had sought to avoid imposing preconceived notions of culture and intercultural competence on the participants in order to uncover their views, the theoretical positioning of the research team was informed by the recent research literature. This has broadly taken the view that culture is not derived from specified and fixed groups of people united by a set of shared practices and ways of knowing, as, for example, suggested in the work of Hofstede (2003), but is 'a dynamic and interactive process' (Baumann 1996, cited in Holliday, Kullman, and Hyde 2017, 73) that is 'inherently fluid, shifting and perspectival, that is: always intercultural' (Dervin and Risager 2015, 5). This fluidity arises because culture is 'situated in, and constantly changing and evolving according to, the many communicative situations that form a part of living in a highly malleable globalized society' (Jenks, Bhatia, and Lou 2013, 121). In short, culture is envisaged as an emergent process that takes place through interaction.

According to this perspective, language, as a key means by which social practice takes place, is an inextricable part of that process. Culture, it has therefore been argued, is discursively constructed (Kramsch 1998; Piller 2012). However, language is not a neutral medium. Every utterance carries with it the history of previous configurations and meanings; every text is a palimpsest of past use. Language can be seen, therefore, as both 'a repository of culture and a tool by which culture is created' (Hall 2012,16) and means that 'in our every communicative encounter we are always at the same time carriers and agents of culture' (Hall 2012 , 45). Thus there is a dichotomy between the conceptualisation of culture as an evolving process and the 'baggage' of cultural reifications inherent in language use, which can to a very great extent delimit meaning or interpretation.

Moreover, it has been acknowledged that a perspective of culture as processual may lack explanatory power when considering the lived experience of individuals. As Jones $(2013,238)$ has observed, 'as much as culture is a verb, it is also, in a very real sense, a noun, and for many people the solidity of its substance is hard to escape'. That is to say, the dynamic process of cultural interaction is constrained (although not determined) by the residues of past creativity. These residues may take many forms, but among them, and particularly salient to the study reported in this paper, is the construction of categories.

Categorisation of individuals and groups is a necessary part of human activity, given the mass of information we are required to process in our lives (Brown 1995), but categories are always underdetermined, created through the grouping of a limited number of attributed features. Therefore, essentialising and stereotyping 'would appear ... to be a by-product' of categorisation (Woodin 2010, 226). What is more, as soon as a categorical distinction between people is made, the potential exists for othering - the process of creating a psychological distance between one's own created group ('us') and other groups that are seen as different in some way ('them'). The potential also exists, from a linguistic perspective, for'discursive discrimination' (Boréus 2006), a practice which has been identified as involving, inter alia, 'exclusion from discourse' and 'negative other-presentation' (Boréus 2006, 405). 
These arguments, which illustrate 'the paradox of culture in the era of globalization' (Jones 2013, 243) helped inform the project team's approach to the study reported in this paper and reinforced the importance of language in any consideration of intercultural issues. Thus, our shared understanding of culture as discursively constructed underpinned the decision to explore participants' use of language as they described their experiences and practices, while our understanding of culture as a contextually-derived emergent process taking place within structures formed from the outcomes of past cultural interactions led to a decision to follow an inductive, data-driven approach to the study. This concurs with the view that the principles of intercultural competence 'can be derived inductively, emerging from the analysis of sets of empirically collected data' (MacDonald and O'Regan 2011, 559).

The understanding of culture as discursively constructed was interconnected with a theoretical view of language as socioculturally situated (Gee 2001) and pragmatic, in the sense described by Verschueren $(2009,19)$ : 'a general functional perspective on (any aspect of) language, i.e. as an approach to language which takes into account the full complexity of its cognitive, social, and cultural (i.e. 'meaningful') functioning in the lives of human beings' [italics in original removed]. This is a position which explains the frequent linking of research into culture with language analysis: 'discourse is a prominent area of investigation in intercultural communication research because it is the main semiotic vehicle in which interactants construct, negotiate, and sometimes contest, culture and identity' (Jenks, Bhatia, and Lou 2013, 122).

\section{Methods}

The project was exploratory-interpretive in nature and followed an 'embedded multiple-case design' (Yin 2014) of eight cases within one university. Each individual case comprised students and staff involved in one of the postgraduate taught programmes offered by the university. The choice of eight cases was made to ensure that the project included programmes from across all of the university's four teaching faculties, which together included the major disciplinary areas of humanities and social sciences, management, engineering and design, and science. The selection of postgraduate programmes only was predicated on the assumption that student participants would be more likely to have a greater level of experience in higher education and intercultural environments than undergraduate students because of their greater diversity in terms of background, since postgraduate study at the research site tends to attract a large number of students from around the world.

For each case there were three forms of data collection: preliminary interviews with staff participants, stimulated recall interviews with the same staff using a recorded classroom observation as a stimulus, and focus group interviews held with students undertaking the programme taught by the staff interviewee. The preliminary interviews explored participants' experience and stated educational approach within their programme from an intercultural perspective, while the stimulated recall interviews were intended to elicit comments on participants' teaching and learning practices that were relevant to the research objectives. Key incidents and uses of language, selected by the project team, were identified from the recordings and used as the stimulus, although interviewees were also invited to make further comments on the recorded lecture or seminar as they wished. The focus group interviews comprised student volunteers who had attended the recorded lecture or seminar and who had responded to written invitations which were distributed at the end of the class by a member of the research team. The number of students within each focus group varied according to their availability and willingness to participate and also to the overall size of the class.

It should be noted that the language used in the classes served solely as a stimulus for the interviews and did not form part of the analysis, except when it was referred to in 
interviews. This was because the study sought to explore inductively the views and perspectives of participants on intercultural communication from an emic perspective, and also because the research team wished to avoid any implication that participants were to be 'judged' on their lectures. Staff participants were therefore assured that the recordings would only be used as an aid to data collection.

In total, eight staff and 24 students took part in the project. All staff were UK residents, although five had originally lived elsewhere, while the students indicated that they came from a variety of countries, such as China, India, Lebanon, South Africa, the United States, Vietnam and Thailand.

The data were analysed through two separate processes, linked methodologically through the theoretical position taken by the project team of language as a sociocultural, pragmatic instantiation of cultural interaction. The first process of thematic analysis was followed by a subsequent, targeted, process of textual analysis (Willig 2013) that was used as a tool to help the project team shift perspectives and capture the ways in which participants used language to bring into being the concepts they discussed. The textual analysis presented below focuses on metaphors, pronouns and register/style produced by the participants within the interviews as well as in the classroom observations. These were not the only aspects of 'discourse' - in the textually-oriented sense of the term as described by, for example, Fairclough (2003) and Paltridge (2012) - identified within the study. However, they were the most salient and prominent features identified by the participants themselves when discussing classroom language choices in relation to the promotion or inhibition of intercultural competence. They were also the richest in terms of data to illustrate the findings in a single paper. Analysis of the individual cases was followed by a cross-case analysis, and it is the findings from this final stage, incorporating both thematic and textual analysis, that are described in this paper.

In the results presented below, quotations from participants are identified through the following coding system: A, B, C and D for the different faculties, divided into two for each of the two programmes (e.g. A1, B2). This is followed by the data collection technique (PI for preliminary interview, FG for focus group, SRI for stimulated recall interview).

\section{Findings and discussion}

The findings on participant understandings of culture and interculturality derived from the thematic analysis have been described in detail elsewhere (McKinley et al. 2019) and so are only briefly summarised in this initial part of the findings section. The main focus in this paper is on the way in which the language used by participants helped address the research objectives of identifying how intercultural competence was understood and how its development was perceived within educational practice. It combines the different forms of evidence obtained from both thematic and textual analysis: (a) participants' descriptions in interviews of how language use in their classes related to interculturality and how it facilitated or inhibited the development of intercultural competence; and (b) aspects of participants' own language use in the interviews that reinforced and complemented the themes derived from the broader thematic analysis of the data.

Thematic analysis revealed that there was considerable overlap of ideas regarding staff and students' explicitly stated understandings of culture and their explanations of intercultural competence. For example, for many of the participants, culture and intercultural issues were explicitly linked to nationality or broad geopolitical grouping, the institution, academic discipline, shared interests and, occasionally, character trait - an example of the latter being the description by participants from the engineering faculty of themselves as being 'unsociable'. Of these categorisations, the overwhelming majority of participants 
linked culture to nationality, and intercultural communication to interaction between people from different countries or language backgrounds. These results are unsurprising, not least because they have been well-documented elsewhere, and because 'intercultural' has so often in daily discourse become inextricably associated with 'international'. In addition, as Piller $(2012,6)$ has pointed out, 'the discourses of national identity and national belonging are powerful ones that have been around for a considerable period and are powerfully supported by a range of state, media and other institutional practices'.

The results also indicated a strong concordance among participants when it came to describing the nature of intercultural competence within the context of their programmes. The features most strongly identified as being associated with it were: valuing and encouraging diversity, critically reflecting on and challenging one's own assumptions and preconceptions, engaging in communicative practices that enhanced access and inclusion, and promoting student autonomy. Some of these features reflect observations from the scholarly literature. For example, Barrett et al. $(2013,7)$ describe intercultural competence as the 'combination of attitudes, knowledge, understanding and skills' which enable the development of constructive relationships and appropriate interactions with those who 'are perceived to have different cultural affiliations from oneself', and Crichton and Scarino (2007, 19-20) define student intercultural competence as the capacity 'to recognise knowledge in its cultural context ... and to communicate and interact effectively across languages and cultures'.

\section{Use of metaphors}

The analysis of metaphors used by participants was influenced at a broad level by conceptual metaphor theory (Lakoff and Johnson 1980). Nevertheless, it was acknowledged that conceptual metaphors in discourse have a limited explanatory capacity (Kimmel 2010) and that 'metaphor construction and interpretation could well involve ad hoc processes influenced by pragmatic and situational factors' (Tay 2017, 99).

One particularly predominant metaphor for culture was that of space or place, especially when place was envisaged as a site of belonging, and reflects such a use in the scholarly literature, from Bhabha's (1994) 'third space' to the present day. For example, one student identified people as being 'from different cultures' (A1, FGI); and a lecturer described addressing cultural issues by telling students that a seminar 'is your space, so you shouldn't be shy to make the best use of this space' (B2, PI). Another lecturer spoke in a disappointed way about the lack of 'a meaningful space for intercultural dialogue' (B1, PI).

In this study, place was also bound up with containment, since there were multiple and frequent references to positioning 'inside' or 'outside' a range of phenomena associated with that sense of belonging: nationhood, institutional, programme or class membership, and working groups within a class. For example, one student spoke of the challenge of being 'outside from my country' (C1, FGI), another expressed an interest in meeting people from 'outside the EU' (B1, FGI), and another said that she liked 'to live in many different cultures' (A1, FGI). One staff member spoke of a student 'sitting outside' (B1, SRI) the rest of the cohort in terms of classroom interaction, and another spoke of attempting to ensure diversity in the composition of student teams - 'a big nice mix of students within [each team]' (C1, PI). The metaphor of containment was also used specifically in relation to culture, with one student speaking of how to 'get into that culture' (A1, FGI), while another expressed a desire to 'fit into their culture' (A1, FGI).

Sometimes participants emphasised containment by describing the boundaries they envisaged as separating groups of people. For example, one student suggested activities should be introduced to 'break the wall' between local and international students (C1, FGI) and another spoke of informal interactions as helping to 'get over' her own perceived cultural 
issues (C1, FGI). Lecturers, too, spoke of 'cultural boundaries' between nationalities (C1, SRI), with one discussing 'crossing that barrier' in his classes to reach out to 'Asian students' (B2, PI).

However, one lecturer consciously rejected the culture as container metaphor. This participant stated that cultures 'are not like little boxes separate from each other' (A2, SR1). The lecturer stated that he deliberately drew on this container metaphor in his teaching practice to help build intercultural competence, or as he put it, 'break those myths that these cultures are watertight' (A2 SRI). He expressed the hope that at the end of his lecture he had conveyed a sense of the human, that his subject area was no longer a 'black box' for students.

Culture was also widely described as a 'perspective', and intercultural competence as the capacity to see the world from different perspectives. One lecturer, asked about his use of stories in his classes, taken from the class observation material, responded: 'Yeah I always find that these anecdotes and stories do help broaden [students'] minds about understanding ... the other side's perspective and seeing yourself from that perspective as well as your own perspective' (A2, SRI). The success of his choice of metaphor in helping to build intercultural competence was evidenced in the language of one of his students, who had clearly taken this image on board, describing the development of intercultural competence as learning about different perspectives: 'the intercultural level was in every class ... the perspective is the most important thing, so it's not about the theory but it's perspective because you know that one's enemy is another person's hero' (A2, FGI). On another programme, one student criticised the lack of intercultural elements within his programme through the metaphor of perspective: 'I personally find it 100 per cent Eurocentric with some South African references thrown in ... there's not a lot of patience I don't think from the instructors for different perspectives' (B1, FGI). Another participant in that focus group felt that she had developed a new perspective through her interaction with other students: 'my peers were from various backgrounds and were involved in various aspects of [the discipline], and for me it works because what it does is open to my eyes to much more than what I was thinking about and what I knew existed' (B1, FGI).

Undergoing cultural change, whether in the form of developing intercultural competence or cultural adaptation, was described by both staff and students as difficult. They used metaphors such as 'struggle', 'fight' or 'challenge', particularly when it came to changing cultural preconceptions. For example, one lecturer felt the need for his students 'to be put in a place where they can challenge their preconceptions and sometimes their prejudgements' (A2, PI), and later spoke of his teaching as 'provoking' his students (A2, SRI). Another lecturer commented: 'I think a lot of [students] come with preconceptions and I think the thing is to break some of them' (D2, SRI). One lecturer, when referring to what she had termed the institutional culture, stressed the difficulty students had in adapting: 'I'm particularly aware of ... the challenges that students will be likely facing ... it's not just the non-UK students even some UK students, especially this year I am seeing some students struggling' (C1, PI). Staff also described their own or their colleagues' difficulties in managing intercultural communication. As one lecturer explained:

I see colleagues who maybe never really left the UK from a work perspective who struggle to interact with people overseas just because they don't know, simple things if somebody doesn't understand what you're saying don't speak louder and faster try to explain it in a different way, I think that comes from an intercultural aspect. (D2, $\mathrm{PI})$

Students, too, described the process of change in terms of a struggle, with one international student suggesting that "maybe some people should be more appreciative of the struggle that 
we have to go through a bit more' (C1, FGI). In that same focus group interview, however, other students embraced difficulty as strength-building, with another participant commenting: 'the most thing that you challenge is yourself, not even the culture round you, so challenging sometimes makes you learn more ... and it makes you stronger' (C1, FGI).

While the quotations above emphasised the process of individual change, some staff participants used metaphors to describe the difficulty of promoting a classroom environment that enhanced access and inclusion. One participant, when responding to a question about an extract on the video recording of his lecture, suggested that, paradoxically, he had to exclude from the classroom discussion those who had been monopolising the interaction:

How does it support the development of intercultural competence? One of the things that was challenging for me was the participation at that point [of the lecture] tended to mainly be white males, and it was pretty hard to get women and people of colour, you might say, into the conversation. I had to suppress them to let others speak. (B1, SRI)

What this lecturer had been seeking to achieve was 'to try to balance participation' (B1, SRI). This kind of language, containing images of balance, symmetry and levelling, particularly in the sense of a rejection of hierarchy, was commonly used by participants when discussing the kind of environment they valued, or when describing the achievement of intercultural competence. For example, one lecturer stated:

After my courses I think people don't take as given many of the things that, for example, the media presents as given. I mean, very often they realise, for example in the relationship between let's say Western European people and let's say the Muslim world is that they realise there is a certain symmetry, whereas before they felt that there's a security threat somewhere ... and could not see their perspective as symmetrical to our perspective. (A1, PI)

Another lecturer described how UK-based students would undergo change when exposed to the experiences of their peers from other countries, expressing their intercultural development as a form of levelling:

And then the English individuals you know first of all I think take pity on the experiences of the African guys, but then learn again to understand that in fact probably what they're doing is a damn good job compared to the limited amount of resources and corruption and everything. So I think it's that levelling act of understanding. (B2, PI)

One participant described how he framed his questions so that students would want to answer them rather than feel compelled to do so. In his view, 'in their culture they have to respond to authority, and so I feel ... I'm trying to find that balance with asking questions and that they answer because they want to answer' (B2, PI). One student participant also spoke of the value of balance in intercultural interactions at a professional level: 'It is good to have a balance in the team when you are working for other people' (D1, FGI). Another student envisaged balance as a desirable outcome with regard to lecturers' classroom language use with those who did not have English as their first language: 'it's not just the language but it's the speed as well ... some people are good at it and better than others to have to find that right balance between the speed with which they explain things' (C1, FGI). 
For one staff participant, levelling, as a reduction of power distance, was explicitly articulated as a desirable outcome in achieving successful intercultural interaction: 'I think communication works ... better between equals' (A1, SRI). In his classes, this belief was embodied through his described approach to teaching that encouraged his students to question their teacher's authority: 'if they take this hierarchical approach, they don't critically engage with my teaching, that means basically that they don't learn as much as they would if they constantly kind of thought maybe I'm wrong here' (A1, SRI).

Some uses of metaphorical language describing the growth of intercultural competence were more associated with movement, although these were much less common. For example, there were several references to it as being a 'journey of exploration' (A2, PI) and one staff participant described the students in her class as merging: 'they gelled beautifully as a team' (C1, PI).

In summary, what these metaphorical uses of language seemed to indicate was that 'cultures' tended to be seen as circumscribed entities. However, although they were described as having borders, these did not appear to be permanent; rather, boundaries were largely described as penetrable in some way. Becoming interculturally competent was often identified with developing a new way of seeing, an alternative perspective that was achieved by engaging with difference. That process was widely described as involving struggle, with the ultimate goal being a kind of equilibrium.

\section{Pronoun use}

The discursive construction of community membership was particularly evident through participants' pronoun use. Indeed, a number of staff participants made reference to their conscious choice of pronouns during their lectures, appearing to draw on theories such as those underpinning the Common Ingroup Identity Model, a strategy by which perceived group boundaries are removed by re-categorisation of members into one single group (Dovidio, Gaertner, and Saguy 2007; Gaertner et al. 1993). As one participant observed: 'I often use the word "we" in the class because I want it to be a feeling in my students that we're all participating in the process ... I'm referring to them and me and our shared perceptions' (A2, SRI). Another lecturer from the same faculty provided a similar explanation for his pronoun use on the recordings:

For me when I present something critical I use this rhetorical strategy that avoids being marginalised, when I say something bad about Westerners, I always say 'us Westerners' because then that doesn't sound so bad ... if a scholar starts being systematically critical or something he's a traitor and his speech is marginalised, so if I talk about 'us' you cannot marginalise me anymore, so it's a rhetorical strategy. (A1, SRI)

Thus, by identifying himself as a member of the group he was criticising in his lectures, this participant argued that he would not leave his commentary open to interpretation as an attack on his listeners and therefore dismissed. For both these lecturers, the promotion of perceptions of in-group membership helped create the conditions for the development of intercultural competence: inclusion and engagement.

The pronouns used within the interviews themselves did not follow this inclusive approach. There are likely to be many reasons for this, not least because the qualitative interview is 'a partly shielded situation where both parties agree to enter into a particular communicative form' (Cruickshank 2012, 43); one that is unlikely to reflect the language of the settings being described by participants. Nevertheless, it was instructive to examine the 
different categories of people that were identified, and note how these were reinforced through pronoun use. Many uses were unremarkable, for example when distinguishing between roles (e.g. 'us' for staff; 'them' for students). However, there were instances where pronouns appeared to be used to highlight identifying traits considered to be characteristic of an in-group or out-group, particularly in relation to negative other-presentation (Boréus 2006). These instances are described below.

Of the eight staff participants, the majority described students in their classes in generic terms. However, two attributed certain traits to categories of students. One of them described 'Asian students' as 'shy to be drawn out ... if you can get them to cross that barrier I think it works for all of us' (B2, PI). In this case, the referent for the pronoun 'us' was not articulated. The same interviewee also later specifically referred to 'Chinese students' as 'shy or resistant or hesitant' and spoke of his attempts to 'get them to engage' (B2, SRI). The other interviewee also referred to 'Chinese students' as having language difficulties and as a consequence 'they're just recipients of a lecture' (D2, PI). This identification of Chinese students as distinct group within the class was echoed by a student participant in that lecturer's class, who commented: 'I think there is a big language barrier between them and everyone else so they prefer sticking together' (D2, FGI).

As shown above, student participants also sometimes referred to categories based on nationality, that of Chinese in particular. This was not a unidirectional phenomenon, however, as the comment from one Chinese student participant illustrates:

We stick to our circle so sometimes I can't find chance to communicate with other students from different countries, and I think some of international students from UK or other countries are not willing to communicate with us - we are a big circle. (B2, FGI)

The identification of one particular nationality rather than any others may reflect the demographic composition of some postgraduate taught programmes at the institution, since recruitment at the research site mirrored the clear shift in recent years towards the recruitment of students from China. In general, though, the categories raised were broader, distinguishing between 'international' and 'local' students. For example, one participant stated 'it's completely different thinking, their norms their cultures are completely different from what I'm used to' (A1, FGI). In an example of what van Dijk (1993) describes as positive selfpresentation and negative other-presentation, one (international) student commented: 'with no disrespect to any of the local students or anything but 'how many of them can do what we are doing?' (C1, FGI), the rhetorical question incorporating a pragmatic presumption of 'shared knowledge on the part of interlocutors and the ongoing discourse in which the presumption occurs' (Flowerdew and Leong 2010, 2242).

One focus group participant suggested a further grouping, resulting in three categories: 'home', 'EU' and 'international' students, when she stated 'I feel that home students are not as curious as, say, EU students ... they [EU students] are more curious to know about where we [international students] come from ... whereas home students don't ask anything' (C1, FGI). From an entirely different perspective, however, one participant identified a 'we' group based on disciplinary affiliation: 'in [name of discipline] we're not very open - just calculations - it's how our brain works'.

As may be seen from these examples, pronoun use, whether by staff or students, helped reinforce how participants conceptualised group membership within their programme. Some of the staff participants appeared to believe, as their reported and observed use of their language in lectures indicated, that creating an environment of inclusion or 'belonging' was a necessary prerequisite for the development of intercultural competence. One staff participant 
in particular was concerned about the use of language, whether by students or by other staff, that deliberately or unconsciously created or reinforced distinct group boundaries.

\section{Register and/or style}

Register, in the sense of the term as put forward by a number of sociolinguists such as Biber and Finegan (1994), and style, as defined by Trudgill (1992), were identified on multiple occasions in the interviews as factors inhibiting the development of intercultural competence through their effect, whether intentional or not, of reinforcing categories or excluding certain people from participation. For example, one lecturer made a clear distinction between language used to express personal identity and language to achieve mutual communication of meaning. He was concerned about register use, criticising those who used English in UK higher education 'in a way that an ordinary peasant wouldn't understand', which he claimed was common practice in universities. He argued that one could enact one's identity or communicate efficiently but not both, and referred particularly to a Skype exchange between students and an Indonesian activist, where 'some of the questions were so sophisticated that they totally lost [the activist]'. He explained that he raised this issue with students, indicating that 'they should not use their language as a way of enacting hierarchy in a relationship' (A1, PI), his comments reflecting the separate conceptualisations of language-for-communication and languagefor-identification that have been identified in the scholarly literature (e.g. Kirkpatrick 2007).

The same lecturer criticised the register of communication from official university sources, which frequently incorporated acronyms and abbreviations that were incomprehensible to those not in the know, thereby setting up barriers to inclusion:

There should be a kind of investigation ... starting from the fact that when a student comes here that student or staff member is expected to know what this ADCGH is, I mean all these crazy acronyms that might be clear for British staff members and students, but are not clear for foreign students or foreign [staff]. (A1, PI)

Some student participants who had English as an additional language attributed their sense of otherness to the speaking styles of some of their lecturers rather than the register, as illustrated by the comment below:

We [L2 students] don't have like time to catch what they're saying, so sometimes it's not only the language ... but the way they deliver the message ... that's why we tend to get on with certain lecturers, we like them more because both of them are speaking in English, but one person can deliver the message more clearly. (C1, FGI)

However, students who had English as an additional language were far more likely to attribute any intercultural difficulties to their own perceived inadequacies with English. For example, one participant commented 'I find life in the UK is kind of awful difficult because of the language barrier' (B2, FGI), and in the same focus group another commented 'I think the context here is quite difficult for me because of the language problem'. Indeed, several student participants suggested that language was a key component of intercultural competence development, to the extent that the two could not be separated. For example, one student claimed that 'language is everything, and if you can't speak fluently you can't express anything' (A2, FGI). There was less consistency on this issue among staff. One lecturer, acknowledging the increasing linguacultural diversity of the higher education environment, noted that 'it is problematic the way how we can assess student papers too 
much on the basis of how good language they have, I mean if somebody develops brilliant ideas but makes a few grammatical errors, we sometimes are too harsh' (A1, PI). Another argued that what was required was more linguacultural diversity among staff:

Our universities tend to be very focused on Europe and North America and not as much focused on Africa or Latin America or Asia, primarily because you don't have people who speak those languages and who have the ability to bring in different perspectives, people have lived there, people have done research on those regions. $(\mathrm{A} 2, \mathrm{PI})$

On the other hand, one staff participant explained that he struggled to reconcile his teaching to this changing environment. Conflating language capabilities and geographical origin, he commented:

[In lectures I'm thinking] how could I phrase the questions so that they are more easy to understand by the overseas students, and the thing I always have in the back of my mind is if I try and spell out the question more clearly, I'm making it too easy for a native English speaker. (D2, SRI)

One student participant suggested that it was not just register or style but the language code used by others that had the effect of excluding him from participation. He was from the Middle East, and was the only non-Chinese member of a student project group. He commented about his experience during group work: 'It's easier for them to stick together and talk in Chinese and they would understand much better I think this is one big issue that that I have with them' (FGI, D 2).

The choice of this student's peers to communicate in Chinese in front of him in a shared task could be interpreted as multilingual individuals not 'using the linguistic resources available to them in a situation-sensitive manner' (Wei 2011, 1225), as it left the participant feeling 'excluded' (D2, FGI) and resentful. In the focus group interview, for example, he expressed a concern that his peers would switch to English if they wanted to obtain information from him, and then switch back to Chinese once they had the information they needed.

\section{Discussion}

From the data, it may be argued that theories relating to interculturality as described in the recent scholarly literature discussed above (e.g. Dervin and Risager 2015; Holliday, Kullman, and Hyde 2017) have outpaced the concepts of culture expressed by participants. Whilst these theories emphasise fluidity and flexibility in a constantly changing transnationally vibrant world, almost all of the participants discussed culture in terms of the reifications that have widely reported in the research literature for decades. Although this may be an example of what has been designated 'the great disconnect' between current educational research and practice (Dumont, Istance, and Benavides 2010), it may not necessarily be problematic that such conventional views of culture persist. It was not the act of categorisation that led to the issues reported in this study. Instead, it was the manner of dealing with them that had the potential to produce positive or negative consequences. As Woodin $(2010,240)$ observed in relation to her own study: 'cultural categorisation and distinction, then, far from being an act of stereotyping ... can be seen to be an act of opening up possibilities for intercultural communication rather than closing them down'. This can also be argued for the current study. For example, the prioritising of language that denoted identity over that which most 
effectively enabled mutual understanding was criticised as a barrier to intercultural exchanges. On the other hand, the promotion of 'cultural diversity' through the respectful and egalitarian consideration of multinational perspectives in the programmes included in this study was widely recognised as a tool for promoting intercultural competence.

The analysis of the language of the interviews illustrated how differences in the approach to cultural categories, as embodied through language use, might relate to the development or otherwise of intercultural competence. It was valuable to observe, for example, that the metaphor of 'perspective' was used independently by staff and student participants in programme 'A2' in a positive way to refer respectfully to the cultural other, while in programme 'D2' both staff and students, also independently, identified as problematic the language used by Chinese students in that course and held them responsible for creating a barrier to the development of intercultural competence. This suggests a need to recognise the contingency of discourse and therefore construction of notions that have the potential to impact positively or negatively in intercultural settings.

The data also revealed the desirability to participants of achieving a state of balance or equilibrium, and it appeared clear that this was a goal when it came to establishing the conditions for the development of intercultural competence. This was evident in participants' favourable use of metaphors linked to a state of balance, in the conscious reduction of boundaries through pronoun use to create an indistinguishable 'us', and in the opinion expressed that successful communication worked best through 'equals'. Where there was an obvious imbalance, as seen, for example, through the use of different language codes or differing student categorisations such as 'local' or 'international', there was discord, disruption or discomfort among individual participants. In discussing their experience of this discord, as shown above participants were more likely to engage in negative representations of cultural others (Boréus 2006), for example in accusing Chinese students of sticking together or asserting the superiority of international students over local students, thereby further reducing the likelihood that intercultural competence might be achieved.

The findings suggest important implications for higher education institutions which seek to develop a more 'internationalised' environment and more interculturally sensitive modes of pedagogy. If intercultural competence continues to be a recommended graduate attribute, universities need to make staff and students aware of the potential influence that the language of intercultural competence has on the relations between the different members of the university community. The evidence provided from this study on the use of language at a micro level (through the use of metaphors and pronouns) or a macro level (through the adoption of a particular register or style) suggests that promoting language awareness could be a first step towards reducing the gap that was seen in this study to occur between notions of internationalisation and interculturalism and the reality of day-to-day social relations on campus. This could be achieved in many different ways and at multiple levels, for example through the development of an institutional language policy, guidelines for the writing of institutional documents, the integration of language awareness into staff development programmes and study skills courses, and induction programmes.

This study set out to identify how staff and students understood intercultural competence and the ways in which they perceived that it was instantiated, enhanced or inhibited through the teaching and learning practices they experienced. The findings reported in this paper have illustrated the key role that participants' experience of specific language choices had to play in relation to these issues by establishing, perpetuating, reinforcing or challenging the conditions that pertained in the programmes, sometimes intentionally but also on many occasions apparently unintentionally, given that some language choices undermined rather than supported a purported communicative goal. What this study has revealed is the important role that language can play in helping to create the conditions for furthering 
understanding of and developing intercultural competence. It was, however, a small scale study that examined only eight programmes within a single institution, and which used classroom observation recordings as a stimulus for data production rather than data themselves. It would therefore be useful to find out through further research, particularly that which focuses on classroom discourse practices, the extent to which these findings might apply across higher education more broadly

\section{References}

Barrett, M., M. Byram, I. Lázár, P. Mompoint-Gaillard, and S. Phillipou. 2013. Developing Intercultural Competence Through Education. Strasbourg: Council of Europe.

Baumann, G. 1996. Contesting Culture: Discourses of Identity in Multi-Ethnic London. Cambridge: Cambridge University Press.

Bhabha, H. 1994. The Location of Culture. New York: Routledge.

Biber, D., and E. Finegan, eds. 1994. Sociolinguistic Perspectives on Register. Oxford: Oxford University Press.

Boréus, K. 2006. "Discursive Discrimination, A Typology.” European Journal of Social Theory 9 (3): 405-424.

Brown, R. 1995. Prejudice: Its Social Psychology. Oxford: Blackwell.

Byram, M. 2008. From Foreign Language Education to Education for Intercultural Citizenship. Clevedon: Multilingual Matters.

Crichton, J., and A. Scarino. 2007. "How are we to Understand the 'Intercultural Dimension'? An Examination of the Intercultural Dimension of Internationalisation in the Context of Higher Education in Australia." Australian Review of Applied Linguistics 30 (1): 4.1-4.21.

Cruickshank, J. 2012. "The Role of Qualitative Interviews in Discourse Theory.” Critical Approaches to Discourse Analysis across Disciplines 6 (1): 38-52.

Dervin, F., and K. Risager. 2015. Researching Identity and Interculturality. New York: Routledge.

Dovidio, J., S. Gaertner, and T. Saguy. 2007. "Another View of 'we': Majority and Minority Group Perspectives on a Common Ingroup Identity.” European Review of Social Psychology 18 (1): 296-330.

Dumont, H., D. Istance, and F. Benavides, eds. 2010. The Nature of Learning: Using Research to Inspire Practice. Paris: OECD Publications.

Fairclough, N. 2003. Analysing Discourse. Textual Analysis for Social Research. London: Routledge.

Flowerdew, J., and S. Leong. 2010. "Presumed Knowledge in the Discursive Construction of SocioPolitical and Cultural Identity." Journal of Pragmatics 42: 2240-2252.

Freeman, F. 2009. Embedding the Development of Intercultural Competence in Business Education CG6-37. Final Report. Strawberry Hills, NSW: Australian Learning and Teaching Council.

Gaertner, S., J. Dovidio, P. Anastasio, B. Bachman, and M. Rust. 1993. "The Common Ingroup Identity Model: Recategorization and the Reduction of Intergroup Bias." European Review of Social Psychology 4 (1): 1-26.

Gee, P. 2001. "Reading as Situated Language: A Sociocognitive Perspective.” Journal of Adolescent and Adult Literacy 44 (8): 714-725.

Hall, J. K. 2012. Teaching and Researching Language and Culture. 2nd ed. Harlow: Pearson. HEA (Higher Education Academy). 2014. Internationalising the Curriculum. York: Higher Education Academy. 
Hofstede, G. 2003. Culture's Consequences: Comparing Values, Behaviours, Institutions and Organizations Across Nations. London: Sage.

Holliday, A., J. Kullman, and M. Hyde. 2017. Intercultural Communication. An Advanced Resource Book. 3rd ed. London: Routledge.

Jenks, C., A. Bhatia, and J. Lou. 2013. "The Discourse of Culture and Identity in National and Transnational Contexts." Language and Intercultural Communication 13 (2): 121125.

Jones, E. 2013. "Internationalization and Employability: The Role of Intercultural Experiences in the Development of Transferable Skills." Public Money and Management 33 (2): 95-104.

Kimmel, M. 2010. "Why we Mix Metaphors and Mix Them Well: Discourse Coherence, Conceptual Metaphor and Beyond." Journal of Pragmatics 42: 97-115.

Kirkpatrick, A. 2007. World Englishes. Implications for International Communication and English Language Teaching. Cambridge: Cambridge University Press.

Kramsch, C. 1998. Language and Culture. Oxford: Oxford University Press.

Lakoff, G., and G. Johnson. 1980. Metaphors We Live By. Chicago: University of Chicago Press.

MacDonald, M. N., and J. P. O’Regan. 2011. "A Global Agenda for Intercultural Communication Research and Practice." In The Routledge Handbook of Language and Intercultural Communication, edited by J. Jackson, 553-567. Abingdon: Routledge.

McKinley, J., K. Dunworth, T. Grimshaw, and J. Iwaniec. 2019. "Developing Intercultural Competence in a 'Comfortable' Third Space: Postgraduate Studies in the UK." Language and Intercultural Communication 19 (1): 9-22.

Paltridge, B. 2012. Discourse Analysis. 2nd ed. London: Bloomsbury.

Piller, I. 2012. "Intercultural Communication: An Overview." In The Handbook of Intercultural Discourse and Communication, edited by C. Paulston, S. Kiesling, and E. Rangel, 3-18. Oxford: Blackwell.

Tay, D. 2017. "Metaphor Construction in Online Motivational Posters." Journal of Pragmatics 112: 97-112.

Trudgill, P. 1992. Introducing Language and Society. London: Penguin. van Dijk, T. A. 1993. Elite Discourse and Racism. Newbury Park, CA: Sage.

Verschueren, J. 2009. "Introduction.” In Key Notions for Pragmatics, edited by J. Verschueren, and J. O. Östman, 1-27. Amsterdam: John Benjamins.

Wei, L. 2011. "Moment Analysis and Translanguaging Space: Discursive Construction of Identities by Multilingual Chinese Youth in Britain.” Journal of Pragmatics 43 (5): $1222-1235$.

Willig, C. 2013. "Discourses and Discourse Analysis." In The SAGE Handbook of Qualitative Data Analysis, edited by U. Flick, 341-353. London: Sage.

Woodin, J. 2010. "Cultural Categorisation: What can we Learn from Practice? An Example from Tandem Learning." Language and Intercultural Communication 10 (3): 225-242.

Yin, R. 2014. Case Study Research Design and Methods. 5th ed. Thousand Oaks, CA: Sage.

\section{Appendix}

\section{A: PRELIMINARY LECTURER INTERVIEW PROTOCOL}

(1) Academic background and teaching

- Tell me about your background as an academic (length of service, type of contract, workload responsibilities, and so on). 
- How long have you been involved in this unit?

- How did your ideas about intercultural competence develop? What led you to be interested in it/informed your understanding?

(2) Development of intercultural/transcultural competence in your unit

- What features of intercultural competence do you think postgraduate students need, and why?

- What sort of understanding of the topic do students have at the beginning of the unit and what do they bring to the unit?

- Does the development of intercultural/transcultural competence feature in your unit? If so, how?

- How, if at all, is intercultural/transcultural competence assessed in the unit?

- In what ways have you seen students change by the end of the unit, from an intercultural competence perspective?

(3) Educational value of intercultural/transcultural competence

- Can you think of any barriers to the development of intercultural competence at this university (could be at programme or institutional level)?

- Can you think of anything at the university that is in place to encourage the development of intercultural competence (could be at programme or institutional level)?

- Where do you think intercultural/transcultural competence fits in the student's overall degree?

- What value does this have for their future employment or life?

- In what ways do you think we could improve our practice in terms of developing transcultural competence at the university?

\section{B: FOCUS GROUP GUIDING TOPICS}

- Why they volunteered, what their interest is in intercultural/transcultural issues and their experience of these issues at the university

- their academic programme - its aims and their reasons for enrolling in it

- whether there are any intercultural/transcultural elements in their programme

- what aspects of intercultural/transcultural competence they believe can and should be developed in their programme

- the knowledge and understandings of intercultural/transcultural competence they brought with them at the start of their programme

- how their intercultural/transcultural competence has developed through the programme (whether self-driven or introduced), the extent to which they have changed (for better or worse)

- what the value is of intercultural/transcultural competence for their present or future lives and its role in an academic course

- the kinds of activities, events, approaches that exist or could be introduced at the university that would encourage the development of intercultural/transcultural competence among students 